\title{
Identification of a novel frameshift c.930delG MEN1 germline mutation (p.Glu273LysfsTer7) in a sporadic case of multiple endocrine neoplasia type 1: A case report
}

\author{
HIROMU NARUSE ${ }^{1,2^{*}}$, HIROSHI UMEMURA $^{1^{*}}$ and TOMOHIRO NAKAYAMA ${ }^{1}$ \\ ${ }^{1}$ Division of Laboratory Medicine, Department of Pathology and Microbiology, Nihon University School of Medicine, \\ Tokyo 173-8610; ${ }^{2}$ Health Sciences Research Institute, Inc., Yokohama 240-0005, Japan
}

Received July 29, 2019; Accepted March 5, 2020

DOI: $10.3892 / \mathrm{mmr} .2020 .11596$

\begin{abstract}
Multiple endocrine neoplasia type 1 (MEN1) is a rare genetic disorder that is inherited in an autosomal dominant manner. The characteristics of the disease are the combined occurrence of tumors in glands of the endocrine system, such as the parathyroid glands, pituitary gland and endocrine pancreas. Germline mutations in the MEN1 gene are associated with the occurrence of MEN1 and genetic testing for this gene is generally used as a basis for diagnosis. In this paper, a case of MEN1 in a middle-aged Japanese woman is reported. Direct sequencing analysis of the patient's DNA was performed and it revealed a MENI gene heterozygous germline (NM_130799.2:c.930delG) mutation in exon 5. This deletion/frameshift mutation produced a stop codon in the downstream sequence (NP_570711.1:p. Glu273LysfsTer7). To the best of our knowledge, this is the first report describing the NM_130799.2:c.930delG mutation as the basis for MEN1.
\end{abstract}

\section{Introduction}

Multiple endocrine neoplasia type 1 (MEN1) is a genetic disorder that has an autosomal dominant transmission. It has an estimated prevalence of $\sim 1$ in 30,000. The disease is characterized by the occurrence of multiple endocrine system tumors affecting the parathyroid glands, pituitary gland and pancreatic islets. Some patients may also develop thymic, adrenal

Correspondence to: Professor Tomohiro Nakayama, Division of Laboratory Medicine, Department of Pathology and Microbiology, Nihon University School of Medicine, 30-1 Oyaguchikamicho, Itabashi, Tokyo 173-8610, Japan

E-mail: nakayama.tomohiro@nihon-u.ac.jp

${ }^{*}$ Contributed equally

Key words: frameshift mutation, genetic testing, MEN1 gene, multiple endocrine neoplasia type 1 , single nucleotide deletion cortical, bronchopulmonary or carcinoid tumors, as well as angiofibromas, lipomas, collagenomas or meningiomas $(1,2)$.

Chandrasekharappa et al (3) identified the tumor suppressor gene $M E N 1$ in 1997 . The $M E N 1$ gene (OMIM *613733) consists of 10 exons and it encodes the nuclear scaffold protein menin (4). Menin is a 610 amino acid protein that is involved in regulating gene transcription via the coordination of chromatin remodeling (5). Germline mutations in MEN1 have been associated with the occurrence of MEN1. Sanger sequencing of the MEN1 gene is an effective and established method for diagnosing MEN1 $(1,6,7)$. The present paper describes the case of a patient with MEN1 that was associated with a novel frameshift mutation based on the deletion of a single nucleotide in the MEN1 gene.

\section{Case report}

A 52-year-old woman (II-2; Fig. 1) and her daughter (III-1; Fig. 1) viewed the website of our division and subsequently visited Nihon University Itabashi Hospital to receive genetic testing and counseling in July 2016. The mother (II-2; Fig. 1) had already been diagnosed with MEN1 in another hospital. Her family and medical history were obtained by interviewing her and drawing the pedigree, shown in Fig. 1, according to the Standardized Human Pedigree Nomenclature by the National Society of Genetic Counselors (8). She developed hypercalcemia five years previously and visited a general hospital. She underwent examinations to detect the cause of hypercalcemia and a single parathyroid tumor was identified. She received a minimally invasive parathyroidectomy and the resected tumor was pathologically revealed to be an adenoma. She was subsequently diagnosed with primary hyperparathyroidism. Brain magnetic resonance imaging (MRI) indicated there was a $2 \mathrm{~mm}$ pituitary microadenoma. Abdominal computed tomography and MRI also detected a $10 \mathrm{~mm}$ tumor in the pancreas. These two tumors were not associated with any endocrine disorder; therefore, they were surveilled using radiological and laboratory tests. Hyperparathyroidism and the parathyroid adenoma did not recur for five years. The patient's father (I-1; Fig. 1) died due to laryngeal cancer at the age of 59 years. The patient's daughter (III-1; Fig. 1) underwent medical examinations that included blood tests every year and was never diagnosed with hypercalcemia. In addition, no 
Table I. Sequence of primers.

\begin{tabular}{lll}
\hline Exon & \multicolumn{1}{c}{ Forward primer } & \multicolumn{1}{c}{ Reverse primer } \\
\hline Exon 2_1 & 5'-GAACCTTAGCGGACCCTGGGAG-3' & 5'-GAAAGTAGGTGAGGCCGCCAGG-3' \\
Exon 2_2 & 5'-AGCATTTTCTGGCTGTCAACC-3' & 5'-AAGGGTTCTGTAAACCATGGAGG-3' \\
Exon 3 & 5'-CCTTTCCCCATGTTAAAGCAC-3' & 5'-GTGGCTTGGGCTACTACAGTATG-3' \\
Exon 4 & 5'-CTTTTCCTGGCTGTCATTCCCTG-3' & 5'-GTCCCACAGCAAGTCAAGTCTGG-3' \\
Exon 5 and 6 & 5'-CGATAGGCTAAGGACCCGTTCTC-3' & 5'-CCCTGCCTCAGCCACTGTTAGG-3' \\
Exon 7 & 5'-CATTTGTGCCAGCAGGGCAGCT-3' & 5'-GAGGGTGGTTGGAAACTGATGGAG-3' \\
Exon 8 & 5'-CCGATGGTGAGACCCCTTCAGACC-3' & 5'-CAGCCCCCATGGCCTGTGGAAG-3' \\
Exon 9 & 5'-CTCTGCTAAGGGGTGAGTAAGAGAC-3' & 5'-CTGGGCCAGAAAAGTCTGACAAGC-3' \\
Exon 10_1 & 5'-GGTCCTGGAGTTCCAGCCACTG-3' & 5'-CTGGAAAGTGAGCACTGGACCCT-3' \\
Exon 10_2 & 5'-AAGCCTCCTGGGACTGTCGCTG-3 & '5'-GCTCAGAGTTGGGGGACTAAGG-3'
\end{tabular}

।

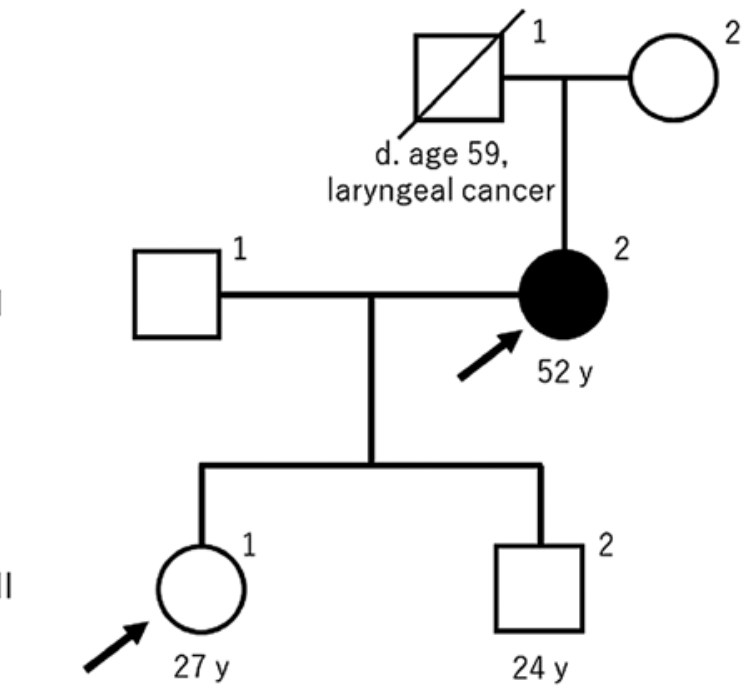

Figure 1. Pedigree of the family, including the present case. Squares denote males and circles denote females. The proband patient with MEN1 is indicated by a black filled circle. The proband patient and her daughter are also indicated by arrows because they underwent genetic counseling and testing. The proband's father died due to laryngeal cancer at age 59 years. d., deceased individual; $y$, age in years of the person at the time of genetic counseling.

other members of the patient's family, including her father and daughter, showed any symptoms of MEN1.

Blood samples $(7 \mathrm{ml})$ were obtained from both the patient and her daughter, and they received genetic counseling from a clinical geneticist. Unfortunately, the patient's son (III-2; Fig. 1) lived far away and he did not agree to undergo genetic testing. An aliquot of the blood $(1 \mathrm{ml})$ was processed by QIAamp ${ }^{\circledR}$ DNA Blood Mini Kit (Qiagen $\mathrm{GmbH}$ ) and genomic DNA was isolated. Oligonucleotide primers which were applicable to both amplification by PCR and direct sequencing by the dideoxy method were designed. The sequence of primers are shown in Table I. The concentration of genomic DNA was determined using a NanoDrop OneC Spectrophotometer (Thermo Fisher Scientific, Inc.). The DNA was diluted to a final concentration of $100 \mathrm{ng} / \mathrm{ml}$ using nuclease-free water. PCR was performed using a Veriti ${ }^{\mathrm{TM}} 200$ thermal cycler (Thermo Fisher Scientific, Inc.) with AmpliTaq Gold ${ }^{\circledR} 360$ Master Mix (Thermo Fisher Scientific, Inc.). Genomic DNA was used as the template with primers flanking the target gene. The PCR reaction conditions were $95^{\circ} \mathrm{C}$ for $3 \mathrm{~min}$ followed by 35 cycles of $95^{\circ} \mathrm{C}$ for $30 \mathrm{sec}, 62^{\circ} \mathrm{C}$ for $30 \mathrm{sec}$, and $72^{\circ} \mathrm{C}$ for $30 \mathrm{sec}$. Following PCR amplification, the amplification products were checked by agarose gel electrophoresis and purified using an ExoSAP-IT purification kit for PCR products (Affymetrix; Thermo Fisher Scientific, Inc.). The purification reaction conditions were $37^{\circ} \mathrm{C}$ for $15 \mathrm{~min}$ and $80^{\circ} \mathrm{C}$ for $15 \mathrm{~min}$. Bidirectional sequencing was performed using forward and reverse primers. The reaction was carried out in a Veriti ${ }^{\mathrm{TM}} 200$ thermal cycler using a BigDye ${ }^{\circledR}$ Terminator v1.1 Cycle Sequencing kit (Thermo Fisher Scientific, Inc.). The reaction conditions were $96^{\circ} \mathrm{C}$ for $1 \mathrm{~min}$ followed by 25 cycles of $96^{\circ} \mathrm{C}$ for $10 \mathrm{sec}$ and $60^{\circ} \mathrm{C}$ for $2 \mathrm{~min}$. The sequencing reaction products were purified using a BigDye Xterminator $^{\mathrm{TM}}$ Purification kit (Thermo Fisher Scientific, Inc.). Amplicons were examined with a direct sequencing apparatus and protocol according to Sanger's method (3130 DNA Analyzer; Thermo Fisher Scientific). Sequence data were processed using GeneMapper ${ }^{\mathrm{TM}}$ ID-X software v1.3 (Thermo Fisher Scientific, Inc.) and the sequence results were mapped to the human genome sequence. Reference sequences of the MEN1 gene used in this analysis were NM_130799.2 for mRNA and NP_570711.1 for protein from National Center for Biotechnology Information database (https://www.ncbi.nlm. nih.gov/nuccore/NM_130799.2/; accessed November 8, 2019).

Sequence analysis of the patient's MENI gene revealed a heterozygous c.930delG mutation in exon 5 (Fig. 2A). In the sense strand of the MEN1 gene, nucleotides 929 and 930 were both guanine residues. The single nucleotide deletions were deemed to be c.930delG rather than c. $929 \mathrm{delG}$ according to Sequence Variant Nomenclature, version 19.01, by the Human Genome Variation Society (https://varnomen. hgvs.org/recommendations/DNA/variant/deletion/; accessed November 8, 2019). Sequencing of the antisense strand showed a complementary deletion of cytosine 930 , confirming the analysis of the sense strand (Fig. 2B). Deletion of this single nucleotide caused a frameshift that generated a stop codon in the downstream sequence (NP_570711.1: p.Glu273LysfsTer7; Fig. 3). The tertiary structure of the mutant menin protein predicted using Swiss-Model revealed that the amino acid sequence of the mutant protein was markedly shorter than that of the wild-type protein (Fig. 4) (9). However, analysis of the 

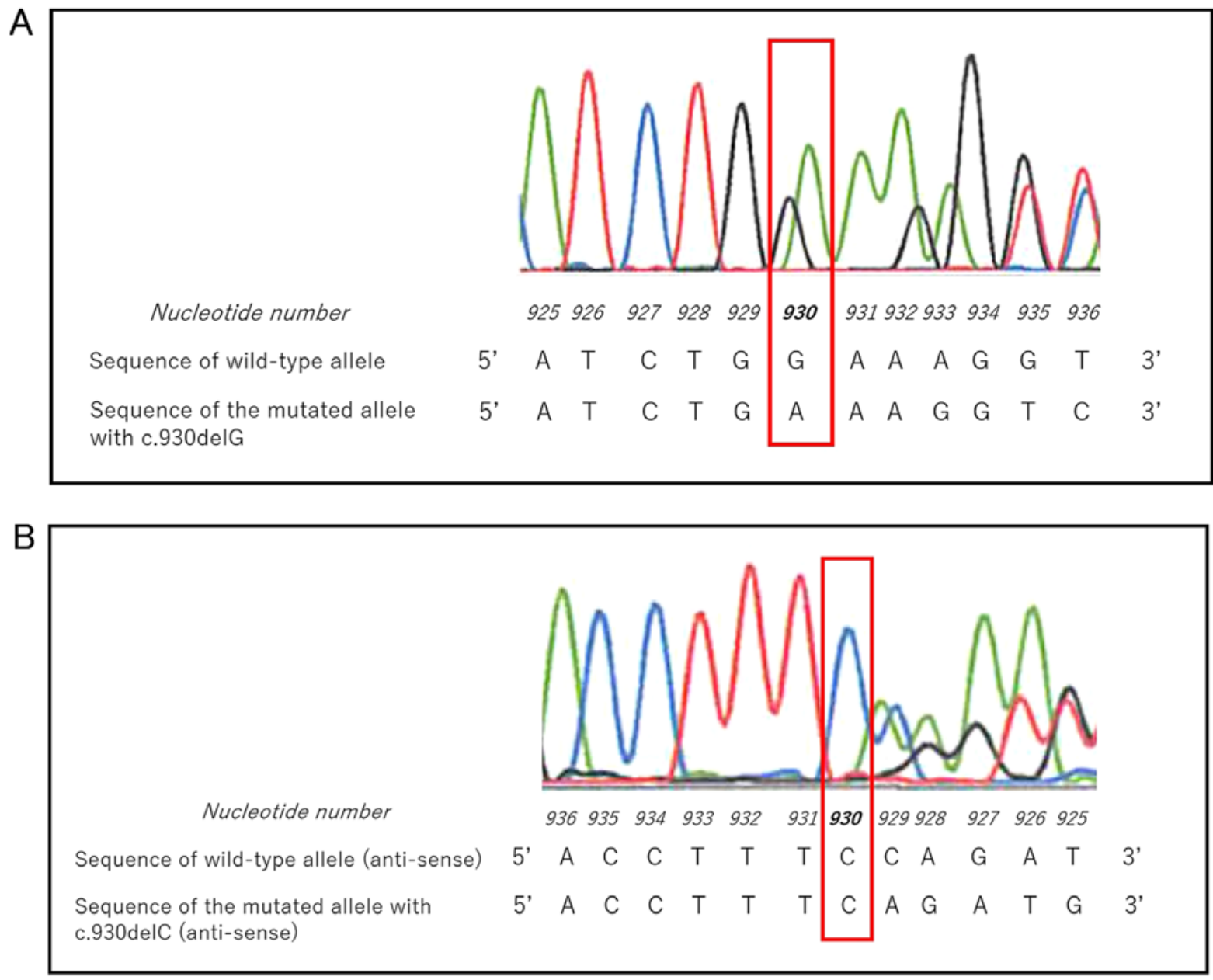

Figure 2. Detection of the pathogenic mutation. (A) Direct sequencing of the multiple endocrine neoplasia type 1 gene revealed a heterozygous deletion of nucleotide 930 guanine in exon 5. (B) Direct sequencing also detected heterozygous deletion of nucleotide 930 cytosine from the antisense strand in exon 5 . This deletion was complementary with the c.930G deletion in the sense strand.

MEN1 gene of the patient's daughter showed no evidence of any mutation, including c.930delG. Considering no particular disease symptoms were present, the patient's daughter was not diagnosed with MEN1.

\section{Discussion}

A novel heterozygous $M E N 1$ gene deletion/frameshift mutation (c.930delG) was identified in a Japanese patient with MEN1. To the best of our knowledge, this is the first report on this mutation.

Diagnostic criteria for MEN1 include the presence of multiple primary MEN1-related tumors (including parathyroid adenoma, entero-pancreatic endocrine tumor and pituitary adenoma) (1,10). As described above, the patient in the present case (II-1; Fig. 1) developed a parathyroid adenoma and a pituitary adenoma. Depending on categorization, the patient had two MEN1-related tumors and was therefore definitively diagnosed with MEN1. The deletion/frameshift mutation identified in the present case should be considered pathogenic.

The definition of familial MEN1 is the presence of at least one MEN1 case plus at least one first-degree relative with one of three MEN1-related tumors (10). As shown in Fig. 1, familial MEN1 was not observed in the present family and the patient seemed to be a sporadic case. Hai et al (11) previously revealed that, even in sporadic cases, the MEN1 gene sometimes has pathogenic mutations, which is similar to the present case. The patient's son (III-2; Fig. 1) did not undergo genetic testing; however, he may be at risk of developing MEN1 in the future.

Some patients with MEN1 who undergo MEN1 gene testing are shown to be negative for a MEN1 mutation (11). De Laat et al (12) analyzed 322 Dutch patients with MEN1 and reported that $90.7 \%$ of cases were MEN1 mutation positive, whereas the remaining $9.3 \%$ were $M E N 1$ mutation negative. Their study also demonstrated that mutation-positive cases were diagnosed earlier (age 33 years vs. age 46 years) and exhibited a poorer prognosis (survival to age 73 years vs. survival to age 87 years) than mutation-negative cases. In addition, mutation-negative patients developed no third primary MEN1-related tumor during the course of follow-up, despite half of the mutation-positive patients showing all three primary manifestations (12). Ellard et al (13) described mutation detection rates of 79,37 and $15 \%$ in patients with three, two and one primary MEN1-related tumor, respectively. Therefore, the mutation detection rate was shown to be associated with the number of MEN1-related tumors (13). The patient in the present case was mutation positive and presented with two primary 
A Amino acid sequence of wild-type menin (NP_570711.1)

MGLKAAQKTLFPLRSIDDVVRLFAAELGREEPDLVLLSLV
LGFVEHFLAVNRVIPTNVPELTFQPSPAPDPPGGLTYFPV
ADLSIIAALYARFTAQIRGAVDLSLYPREGGVSSRELVKK
VSDVIWNSLSRSYFKDRAHIQSLFSFITGTKLDSSGVAFA
VVGACQALGLRDVHLALSEDHAWVVFGPNGEQTAEVTWHG
KGNEDRRGQTVNAGVAERSWLYLKGSYMRCDRKMEVAFMV
CAINPSIDLHTDSLELLQLQQKLLWLLYDLGHLERYPMAL
GNLADLEELEPTPGRPDPLTLYHKGIASAKTYYRDEHIYP
YMYLAGYHCRNRNVREALQAWADTATVIQDYNYCREDEEI
YKEFFEVANDVIPNLLKEAASLLEAGEERPGEQSQGTQSQ
GSALQDPECFAHLLRFYDGICKWEEGSPTPVLHVGWATFL
VQSLGRFEGQVRQKVRIVSREAEAAEAEEPWGEEAREGRR
RGPRRESKPEEPPPPKKPALDKGLGTGQGAVSGPPRKPPG
TVAGTARGPEGGSTAQVPAPAASPPPEGPVLTFQSEKMKG
MKELLVATKINSSAIKLQLTAQSQVQMKKQKVSTPSDYT
LSFLKRQRKGLSTOP

B Amino acid sequence of menin with c.930delG (p.Glu273LysfsTer7)

MGLKAAQKTLFPLRSIDDVVRLFAAELGREEPDLVLLSLV
LGFVEHFLAVNRVIPTNVPELTFQPSPAPDPPGGLTYFPV
ADLSIIAALYARFTAQIRGAVDLSLYPREGGVSSRELVKK
VSDVIWNSLSRSYFKDRAHIQSLFSFITGTKLDSSGVAFA
WVGACQALGLRDVHLALSEDHAWVVFGNGEQTAEVTWHG
KGNEDRRGQTVNAGVAERSWLYLKGSYMRCDRKMEVAFMV
CAINPSIDLHTOSLELLQLQQKLLWLLYOLGLKGTPWPSTOP

MGLKAAQKTLFPLRSIDDVVRLFAAELGREEPDLVLLSLV VSDVIWNSLSRSYFKDRAHIQSLFSFITGTKLDSSGVAFA KGNEDRRGQTVNAGVAERSWLYLKGSYMRCDRKMEVAFMV CAINPSIDLHTOSLELLQLQQKLLWLLYDLGHLKGTPWPSTOP

Figure 3. Comparison of the wild-type and mutated menin protein. (A) Amino acid sequence of wild-type menin protein (NP_570711.1) encoded by the multiple endocrine neoplasia type 1 gene. Amino acids are presented in single-letter code. (B) Amino acid sequence of menin with the c.930delG mutation is shown. The sequences of the mutated and wild type were identical from the N-terminal methionine to leucine 272 . However, the deletion/frameshift mutation generated a stop codon in the downstream sequence (p.Glu273LysfsTer7).

A

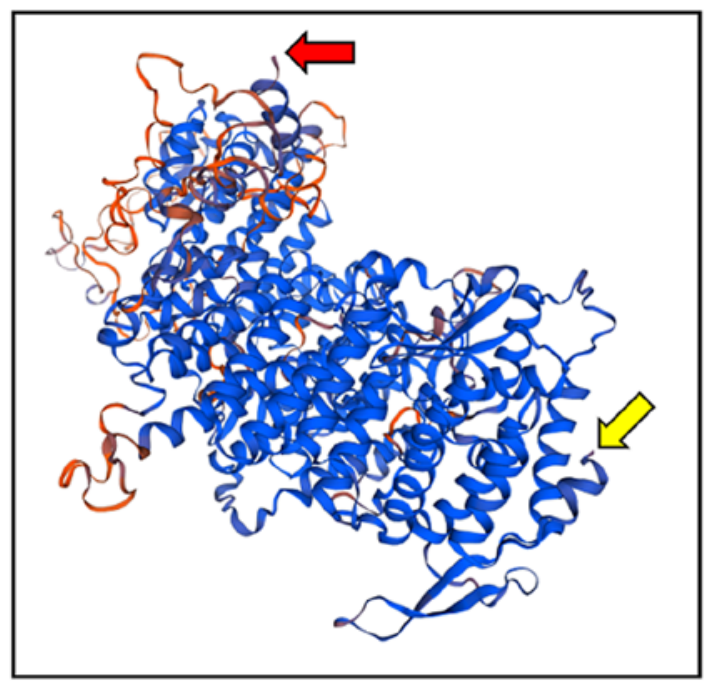

B

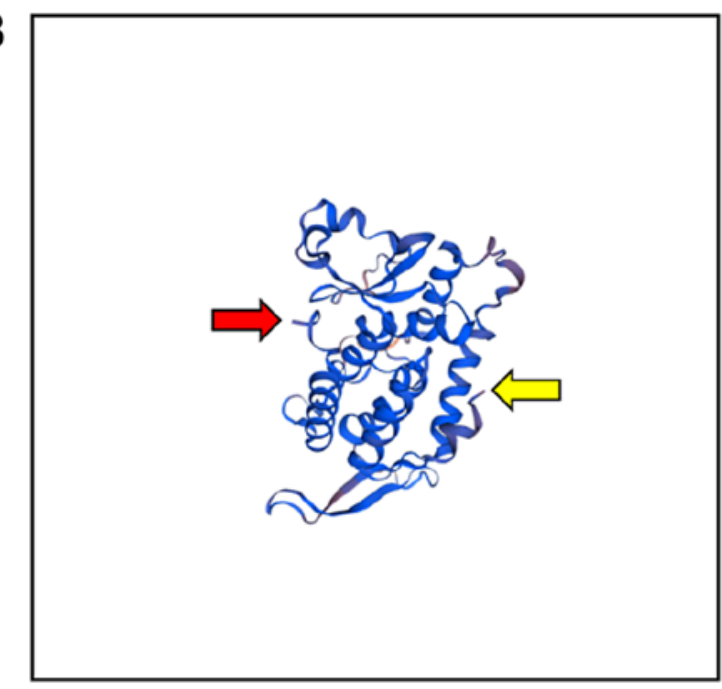

Figure 4. Tertiary structures of wild-type and mutant menin predicted using Swiss-Model. The N-terminus and C-terminus are indicated by yellow and red arrows, respectively. (A) Structure of wild-type menin. (B) Menin with the p.Glu273LysfsTer7 mutation.

MEN1 manifestations. In the future it may be revealed that the patient's pancreatic tumor is a pancreatic endocrine tumor.

Several articles have reviewed previously described MEN1 gene mutations. Marini et al (14) examined over 400 different germline or somatic mutations and reported that $50 \%$ of MEN1 mutations were frameshift mutations, $20 \%$ were nonsense mutations, $20 \%$ were missense mutations and $7 \%$ were splice-site defects. Lemos and Thakker (15) also reviewed 1,133 germline mutations in the MEN1 gene and classified $41 \%$ as frameshift mutations, $23 \%$ as nonsense mutations, $20 \%$ as missense mutations, $9 \%$ as splice-site mutations, $6 \%$ as in-frame deletions or insertions and $1 \%$ as gross deletions. In addition, Concolino et al (16) reviewed 576 MEN1 mutations and reported frameshift mutations in $42 \%$ of the cases, missense mutations in $25.5 \%$ of the cases, nonsense mutations in $14 \%$ of the cases, splice-site mutations in $10.5 \%$ of the cases, in-frame deletions or insertions in $5.5 \%$ of the cases, and gross deletions in the remaining $2.5 \%$ of the cases. These reviews described very similar results, with frameshift mutations representing the most frequent type of mutation at $40-50 \%$. Thus, the novel mutation identified in the present case was in the most frequent class of MEN1 mutations.

The nuclear scaffold protein menin is the product of the MEN1 gene. Menin acts as a tumor suppressor and interacts with numerous proteins, including transcription factor JunD, $\mathrm{NF}-\kappa \mathrm{B}, \mathrm{SMAD} 3$, protein-energy malnutrition, non-metastatic protein 23 homolog 1, replication protein A2, non-muscle myosin heavy chain IIA, Fanconi anemia group D2, paired 
amphipathic helix protein $\operatorname{Sin} 3$, histone deacetylase 1, activator of S-phase kinase and checkpoint suppressor 1 (15). Menin with the p.Glu273LysfsTer7 mutation lacks the amino acid sequence spanning from the middle of exon 5 to the C-terminus, which is hypothesized to be essential for binding with the 11 above-mentioned proteins (15).

It must be noted that the lack of functional experiments to validate the results of the present study is a limitation of this research. Future studies aimed at confirming the pathogenicity of the c.930delG frameshift mutation are thus warranted.

In conclusion, a novel frameshift heterozygous c.930delG mutation in the MEN1 gene that is associated with MEN1 was identified.

\section{Acknowledgements}

Not applicable.

\section{Funding}

The present study was supported by a Grant-in-Aid from the Japanese Ministry of Education, Culture, Sports, Science and Technology (grant no. 16K08978) and by a grant from the Health Sciences Research Institute, Inc., Yokohama, Japan, for the Division of Companion Diagnostics, Department of Pathology of Microbiology, Nihon University School of Medicine, Tokyo, Japan grant no. 20131001).

\section{Availability of data and materials}

The datasets used and/or analyzed during the current study are available from the corresponding author on reasonable request.

\section{Authors' contributions}

HN, HU and TN designed the study. TN supervised the project. HN performed the experiments. HN and HU analyzed the data. HN and HU drafted and wrote the manuscript. All authors read and approved the final manuscript.

\section{Ethics approval and consent to participate}

Genetic testing and the overall study protocol for advanced medical care were approved by the Director of the Nihon University Itabashi Hospital on February 1, 2016, according to the Ministry of Health, Labor and Welfare Japan. Written informed consent was obtained from both subjects prior to collection of the samples, which were used for genomic analysis.

\section{Patient consent for publication}

Written informed consent was obtained from both subjects for publication.

\section{Competing interests}

The authors declare that they have no competing interests.

\section{References}

1. Thakker RV, Newey PJ, Walls GV, Bilezikian J, Dralle H, Ebeling PR, Melmed S, Sakurai A, Tonelli F and Brandi ML; Endocrine Society: Clinical practice guidelines for multiple endocrine neoplasia type 1 (MEN1). J Clin Endocrinol Metab 97: 2990-3011, 2012.

2. Mark SJ: Recent topics around multiple endocrine neoplasia type 1. J Clin Endocrinol Metab 103: 1296-1301, 2018.

3. Chandrasekharappa SC, Guru SC, Manickam P, Olufemi SE, Collins FS, Emmert-Buck MR, Debelenko LV, Zhuang Z, Lubensky IA, Liotta LA, et al: Positional cloning of the gene for multiple endocrine neoplasia-type 1. Science 276: 404-407, 1997.

4. Guru SC, Goldsmith PK, Burns AL, Marx SJ, Spiegel AM, Collins FS and Chandrasekharappa SC: Menin, the product of the MEN1 gene, is a nuclear protein. Proc Natl Acad Sci USA 95: 1630-1634, 1998 .

5. Canaff L, Vanbellinghen JF, Kaji H, Goltzman D and Hendy GN: Impaired transforming growth factor- $\beta$ (TGF- $\beta$ ) transcriptional activity and cell proliferation control of a menin in-frame deletion mutant associated with multiple endocrine neoplasia type 1 (MEN1). J Biol Chem 287: 8584-8597, 2012.

6. Hyde SM, Cote GJ and Grubbs EG: Genetics of multiple endocrine neoplasia type $1 /$ multiple endocrine neoplasia type 2 syndromes. Endocrinol Metab Clin North Am 46: 491-502, 2017.

7. Luo Y, Sun Y, Zhu X and Li X: Analysis of MEN1 c.482G>A (p.Gly161Asp) mutation in a pedigree with familial multiple endocrine neoplasia type 1. Mol Med Rep 16: 8973-8976, 2017.

8. Bennett RL, French KS, Resta RG and Doyle DL: Standardized human pedigree nomenclature: Update and assessment of the recommendations of the National Society of Genetic Counselors. J Genet Couns 17: 424-433, 2008.

9. Guex N, Peitsch MC and Schwede T: Automated comparative protein structure modeling with SWISS-MODEL and Swiss-PdbViewer: A historical perspective. Electrophoresis 30 (Suppl 1): S162-S173, 2009.

10. Brandi ML, Gagel RF, Angeli A, Bilezikian JP, Beck-Peccoz P, Bordi C, Conte-Devolx B, Falchetti A, Gheri RG, Libroia A, et al: Guidelines for diagnosis and therapy of MEN type 1 and type 2. J Clin Endocrinol Metab 86: 5658-5671, 2001.

11. Hai N, Aoki N, Shimatsu A, Mori T, and Kosugi S: Clinical features of multiple endocrine neoplasia type 1 (MEN1) phenocopy without germline MEN1 gene mutations: Analysis of 20 Japanese sporadic cases with MEN1. Clin Endocrinol (Oxf) 52: $509-518,2000$

12. De Laat JM, van der Luijt RB, Pieterman CR, Oostveen MP, Hermus AR, Dekkers OM, de Herder WW, van der Horst-Schrivers AN, Drent ML, Bisschop PH, et al: MEN1 redefined, a clinical comparison of mutation-positive and mutation-negative patients. BMC Med 14: 182, 2016.

13. Ellard S, Hattersley AT, Brewer CM and Vaidya B: Detection of an MEN1 gene mutation depends on clinical features and supports current referral criteria for diagnostic molecular genetic testing. Clin Endocrinol (Oxf) 62: 169-175, 2005.

14. Marini F, Falchetti A, Del Monte F, Carbonell Sala S, Gozzini A, Luzi E and Brandi ML: Multiple endocrine neoplasia type 1. Orphanet J Rare Dis 1: 38, 2006.

15. Lemos MC and Thakker RV: Multiple endocrine neoplasia type 1 (MEN1): Analysis of 1336 mutations reported in the first decade following identification of the gene. Hum Mutat 29: 22-32, 2008.

16. Concolino P, Costella A and Capoluongo E: Multiple endocrine neoplasia type 1 (MEN1): An update of 208 new germline variants reported in the last nine years. Cancer Genet 209: 36-41, 2016. 